\title{
Identification of novel pig and human immunoglobulin G-binding proteins and characterization of the binding regions of enolase from Streptococcus suis serotype 2
}

\section{Quan Li}

Yangzhou University

\section{Yang Fu}

Nanjing Agricultural University

\section{Genglin Guo}

Nanjing Agricultural University

\section{Zhuohao Wang}

Nanjing Agricultural University

Wei Zhang ( $\nabla$ vszw@njau.edu.cn )

Nanjing Agricultural University https://orcid.org/0000-0002-3575-6225

\section{Original article}

Keywords: Streptococcus suis; IgG-binding proteins; surface proteins; interactions; enolas

Posted Date: May 11th, 2020

DOI: https://doi.org/10.21203/rs.3.rs-23090/v2

License: (c) (1) This work is licensed under a Creative Commons Attribution 4.0 International License. Read Full License

Version of Record: A version of this preprint was published at AMB Express on June 1st, 2020. See the published version at https://doi.org/10.1186/s13568-020-01042-2. 


\section{Abstract}

Streptococcus suis, a major emerging pathogen in swine and humans, expresses immunoglobulin G (IgG)-binding proteins (IBPs), which contribute to the ability of organism to evasion of host immune system. The objective of this study was to identify novel pig IgG (plgG) and human IgG (hlgG)-binding proteins and characterize the binding regions of enolase from Streptococcus suis serotype 2 (S. suis 2). Here, four plgG-binding proteins (pIBPs) and five hlgG-binding proteins (hIBPs) were identified from $S$. suis 2 surface proteins by 2D-Far-western blot assays. All the newly captured proteins were expressed and further confirmed their binding activity to plgG or hlgG by Far-western blot and dot blot. In addition to previously identified factor $\mathrm{H}$, fibronectin, collagen, fibrinogen, plasminogen and laminin, we also found that both plgG and hlgG can specifically interact with enolase. Binding assays indicated that interactions of $S$. suis 2 enolase with plgG and hlgG is primarily mediated by the enolase C-terminal portion (Enolase$\mathrm{C}$, a.a. 142-432). We found that hlgG exhibited stronger binding ability to Enolase-C than plgG. Further analysis of the $\mathrm{C}$-terminal regions of enolase (Enolase-C1 and Enolase-C2) suggested that the $\mathrm{C}$-terminus possessed two different binding domains with distinct host IgG proteins. Strikingly, we confirmed that plgG interacted with the Enolase-C1 (a.a. 142-271) and hlgG interacted with the Enolase-C2 (a.a. 271432). These observations of enolase provide interesting insights in the pathogenesis of $S$. suis infection.

\section{Introduction}

Streptococcus suis has emerged as an important zoonotic agent causing serious diseases such as arthritis, endocarditis, meningitis, and septicemia (Feng et al., 2010; Staats et al., 1997). It is also responsible for a series of serious infections associated with meningitis, septicemia, and acute death in humans (Gottschalk et al., 2007). Among the 35 serotypes (types 1 to 34 , and 1/2) depended on the difference of capsular antigens, Streptococcus suis serotype 2 (S. suis 2 ) is the most virulent and prevalent one, responsible for most humans and swine infection cases in Asia and North America. Globally, serotypes 9 and 7 are also the predominant $S$. suis serotypes involved in pig infections (GoyetteDesjardins et al., 2014). In the past, several approaches have been used to explore protective antigens for preventing $S$. suis infection. However, no ideal therapeutics or vaccine against $S$. suis infections is available thus far, although some researches showed homologous protection (Baums et al., 2009; Feng et al., 2014; Fittipaldi et al., 2012). To date, a multitude of virulence factors have been reported, such as MRP (Li et al., 2017b; Wisselink et al., 2001), SLY (Du et al., 2013; Jacobs et al., 1996), EF (Wisselink et al., 2001), enolase (Esgleas et al., 2009; Feng et al., 2009; Zhang et al., 2009), HtpsC (Li et al., 2015a), and HP0272 (Chen et al., 2010; Pian et al., 2012), but the pathogenesis of S. suis infections remains poorly understood (Fittipaldi et al., 2012).

Immunoglobulin G (IgG) is the major antibody of humoral immunity found in extracellular fluid and blood allowing it to protect the host tissues from infection. IgG-mediated binding of pathogen allows their recognition by phagocytic immune cells that results in pathogen elimination. However, a variety of pathogens express surface IgG-binding proteins (IBPs) to recruit IgG to evade the host defences in a nonimmune mechanism (Bessen and Fischetti, 1990; Blumenfeld et al., 1990). IBPs play important roles in 
the capacity of bacterial pathogens to evade lgG-mediated phagocytosis by interfering with complement consumption, phagocytosis or opsonization (Serhir et al., 1993; Widders et al., 1989). The presence of IBPs have been reported on some pathogenic streptococci (Nobbs et al., 2009). A number of IBPs in streptococci of groups $A, B$ and $C$ shown to be important virulence factors, and contribute to escape detection by the immune system, including Sfbl, Sib35, SibA, protein H, Sir, M protein, M-like proteins, and Mrp of S. pyogenes, Lzp of S. agalactiae, Protein G, FOG, MAG, and DemA of $S$. dysgalactiae. Although a multitude of IBPs were found in various bacteria, the research of $S$. suis IBPs was neglected for years. Thus far, only a 52-kDa IgG-binding protein enolase was identified and characterized (Serhir et al., 1995; Serhir et al., 1993). Therefore, large scale identification of the IBPs of S. suis 2 that interact with IgG will provide valuable insights into the mechanism of $S$. suis induced pathogenesis. Far-western blot assay is an efficient method to characterize protein-protein interactions that can be used to identify specific interacting proteins in complex mixture samples. In our previous study, it has been successfully used for the identification of factor $\mathrm{H}$-, laminin- and fibronectin-binding proteins of $\mathrm{S}$. suis 2 ( $\mathrm{Li}$ et al., 2015b; Li et al., 2017c). In this work, four pIBPs and five hIBPs, including enolase, Peptidoglycan-binding protein LysM (LysM), Pyruvate kinase (Pyk), Lactate dehydrogenase (LDH), Fructose-bisphasphate aldolase (FBA), and 3-Ketoacyl-ACP reductase (KAR) were identified from $S$. suis 2 surface proteins using this approach.

Surface proteins on Gram-positive bacteria are often multifunctional molecules with two or more independent functions. Enolase, a conserved surface protein, is multifunctional in its enzymatic activity and can bind different host components found in body secretions, which include plasminogen (Esgleas et al., 2008), fibronectin (Esgleas et al., 2008), fibrinogen (Pian et al., 2015), laminin (Li et al., 2015b), factor $\mathrm{H}$ (Li et al., 2017c), and collagen (Zhang et al., 2014). Previous studies indicated that S. suis enolase can facilitate the adherence to and invasion of host cells (Esgleas et al., 2008; Zhang et al., 2009). Sun et al. had reported that enolase can significantly disrupt the blood-brain barrier integrity by inducing IL-8 release (Sun et al., 2016). Additionally, Feng et al. demonstrated that enolase can function as a protective antigen against $S$. suis 2 infection (Feng et al., 2009). In the present study, we also identified that both plgG and hlgG can specifically interact with enolase. The interactions of enolase specific regions with plgG and hlgG was further evaluated. We found that the binding region of enolase to plgG and hlgG is primarily mediated by Enolase-C. Furthermore, binding assays confirmed that plgG interacted with the Enolase-C1 and hlgG interacted with the Enolase-C2. Taken together, these observations of enolase improved our understanding of the pathogenesis of $S$. suis 2 infection.

\section{Materials And Methods}

\section{Bacterial strains and culture conditions}

The S. suis 2 strain ZY05719 is one of the representative Chinese virulent strains and isolated from a diseased pig during an outbreak in Sichuan, China. The bacteria were maintained in Todd Hewitt Broth (THB; Becton Dicksinson, USA) liquid or agar media at $37^{\circ} \mathrm{C}$ and harvested the mid-exponential phase. E. coli strains were maintained in Luria-Bertani Broth (LB) liquid medium or plated on LB agar at $37^{\circ} \mathrm{C}$. 
When necessary, $100 \mu \mathrm{g} / \mathrm{ml}$ ampicillin (Amp; Sigma) was used for screen the E. coli transformants. The pET-32a vectors were used for protein expression.

\section{Preparation of cell wall and extracellular proteins}

Cell wall-associated proteins were prepared according to our previous study (Li et al., 2015b; Li et al., 2017c). Briefly, the bacteria samples from late stage of exponential phase were separated by centrifugation at $4^{\circ} \mathrm{C}$, and then resuspended in solution buffer containing $30 \mathrm{mM}$ Tris- $\mathrm{HCl}(\mathrm{pH} 7.5), 3 \mathrm{mM}$ $\mathrm{MgCl}_{2}, 125 \mathrm{U} / \mathrm{ml}$ mutanolysin, $25 \%$ sucrose, and incubated for $90 \mathrm{~min}$ at $37^{\circ} \mathrm{C}$. The cell lysate was centrifuged at $4^{\circ} \mathrm{C}$ for $10 \mathrm{~min}$ and the supernatant were precipitated in $10 \%$ trichloroacetic acid (TCA) for $30 \mathrm{~min}$ at $4^{\circ} \mathrm{C}$. The proteins were washed two times with $10 \mathrm{ml}$ chilled acetone to remove the residual TCA, and then dried the pellet in air.

Extracellular proteins were prepared as we recently described (Li et al., 2015b). In short, culture supernatant was separated by centrifugation at $4^{\circ} \mathrm{C}$ and then filtered twice through a $0.22 \mu \mathrm{m}$ membrane filters. Then, the supernatant were precipitated in 10\% TCA for 30 min at $4^{\circ} \mathrm{C}$. The proteins were washed two times with $10 \mathrm{ml}$ chilled acetone to remove the residual TCA, and then dried the pellet in air.

\section{Identification of plBPs and hIBPs by 2D-Far-western blot}

The 2D-Far-western blot experiment was carried out according to our previous study (Li et al., 2015b; Li et al., 2017c). In brief, the cell wall and extracellular protein samples were solubilized in a $250 \mu$ solution buffer containing $0.2 \% \mathrm{w} / \mathrm{v}$ DTT, $2 \mathrm{M}$ thiourea, $7 \mathrm{M}$ urea and $2 \% \mathrm{w} / \mathrm{v}$ CHAPS at $25^{\circ} \mathrm{C}$ for $30 \mathrm{~min}$. The insoluble components were removed with the 2-D Clean-up Kit (GE Healthcare). Subsequently, samples were resuspended in $250 \mu$ rehydration solution containing $0.2 \% \mathrm{w} / \mathrm{v}$ DTT, $2 \% \mathrm{w} / \mathrm{v} \mathrm{CHAPS}, 0.002 \% \mathrm{w} / \mathrm{v}$ bromophenol blue, $7 \mathrm{M}$ urea, $2 \mathrm{M}$ thiourea, and 0.5\% v/v IPG buffer. And then loaded into immobilized pH gradient strips (13 cm; pH 4-7; GE Healthcare) for isoelectric focusing (IEF) analysis.

For Far-western blot analysis, the cell wall and extracellular proteins were subjected to SDS-PAGE, and then transferred onto polyvinylidene difluoride (PVDF) membranes (Merck Millipore). The membranes were blocked for $12 \mathrm{~h}$ with $5 \% \mathrm{w} / \mathrm{v}$ skimmed milk diluted with Tris-buffered saline with Tween 20 (TBST) at $4^{\circ} \mathrm{C}$. After discarding the blocking buffer, membranes were incubated with plgG (Sigma; 20 $\left.\mu \mathrm{g} / \mathrm{ml}\right)$ or $\mathrm{hlgG}$ (Sigma; $20 \mu \mathrm{g} / \mathrm{ml}$ ) for $24 \mathrm{~h}$ at $4^{\circ} \mathrm{C}$. At the same time, a membrane incubated with $20 \mu \mathrm{g} / \mathrm{ml}$ BSA was used as a negative control, followed by three washes with the washing buffer TBST and incubated with HRP conjugated staphylococcal protein A (SPA) (Boster; 1:3,000 dilution) for $1 \mathrm{~h}$ at $37^{\circ} \mathrm{C}$. After three washes, the positive proteins were developed using 3,3'-diaminobenzidine (DAB; Tiangen, China).

\section{Identification of positive spots by MALDI-TOF-MS}

Identification of the positive proteins were carried out according to our previous study (Li et al., 2015b). In brief, the detected protein spots were excised from the gels for digestion and subjected to MALDI-TOF-MS analysis. Peptide mass fingerprinting data were analyzed using the MASCOT server 
(http://www.matrixscience.com). Peptides with a rank of 1 in the MASCOT search were considered significant and used for the combined peptide score.

\section{Expression and purification of recombinant IBPs and enolase truncations}

To express recombinant pIBPs and hIBPs in E. coli, ZY05719 genomic DNA was used for PCR with the primers described in Table 1. S. suis IBPs (Enolase, LysM, Pyk, LDH, FBA, KAR) and enolase truncations (Enolase-N, Enolase-C, Enolase-C1, Enolase-C2) were amplified, and the PCR products were inserted into the pMD19-T and then cloned into the pET-32a vector using BamHI/ Xhol or BamHI/EcoRI restriction enzymes. The pET-32a plasmids with inserts were screened by PCR amplification using primers. The cloned gene sequences were confirmed by direct DNA sequencing. Afterwards, the positive clone was transformed into $E$. coli strain BL21 (DE3) for expression. Bacteria were induced with $1 \mathrm{mM}$ IPTG for $4 \mathrm{~h}$ at $37^{\circ} \mathrm{C}$ when the OD600 was between 0.5-0.6. Bacterial cells were harvested by centrifugation at $4^{\circ} \mathrm{C}$. The recombinant His-tagged proteins were purified by Ni-chelating affinity gel (GE Healthcare) according to the instruction manual. After passage through a $0.22-\mu \mathrm{m}$ filter (Millipore), purified recombinant proteins were stored at $-80^{\circ} \mathrm{C}$. The concentration of recombinant proteins were confirmed by BCA protein assay kit (Beyotime).

\section{Binding assays by Far-Western blot}

The Far-western blot analysis of recombinant IBPs and enolase truncations to plgG or hlgG was carried out according to our previous study (Li et al., 2015b; Li et al., 2017c). In brief, recombinant proteins and casein were subjected to $12 \%$ SDS-PAGE, and then transferred onto PVDF membranes. The membranes were blocked for $12 \mathrm{~h}$ with $5 \% \mathrm{w} / \mathrm{v}$ skimmed milk diluted with TBST at $4^{\circ} \mathrm{C}$. After discarding the blocking buffer, membranes were incubated with plgG (Sigma; $20 \mu \mathrm{g} / \mathrm{ml}$ ) or hlgG (Sigma; $20 \mu \mathrm{g} / \mathrm{ml}$ ) for $24 \mathrm{~h}$ at $4^{\circ} \mathrm{C}$. Subsequently, the membranes were washed three times with the washing buffer TBST and incubated with HRP conjugated SPA for $1 \mathrm{~h}$ at $37^{\circ} \mathrm{C}$. After three washes, the positive proteins were developed using 3,3'-diaminobenzidine (DAB; Tiangen, China). Casein was used as a negative control for non-specific binding to $\lg G$.

\section{Binding assays by dot blot}

The dot blot analysis of recombinant IBPs to plgG or hlgG was performed as previously described (Li et al., 2017a; Lu et al., 2008). Equal volumes (3 $\mu \mathrm{l})$ of recombinant proteins were each spotted in duplicate onto the methanol-activated PVDF membranes. The membranes were air dried for 5 minutes and blocked for $12 \mathrm{~h}$ with $5 \% \mathrm{w} / \mathrm{v}$ skimmed milk diluted with TBST at $4^{\circ} \mathrm{C}$. After discarding the blocking buffer, membranes were incubated with plgG (Sigma; $20 \mu \mathrm{g} / \mathrm{ml}$ ) or hlgG (Sigma; $20 \mu \mathrm{g} / \mathrm{ml}$ ) for $24 \mathrm{~h}$ at $4^{\circ} \mathrm{C}$. Subsequently, the membranes were washed three times with TBST and incubated with HRP conjugated SPA for $1 \mathrm{~h}$ at $37^{\circ} \mathrm{C}$. After three washes, bands were developed using 3,3'-diaminobenzidine (DAB; Tiangen, China). Casein was used as a negative control for non-specific binding to IgG. The membrane with HRP conjugated SPA alone were used as a blank control. 


\section{Results}

\section{Identification of novel S. suis 2 pIBPs and hIBPs by proteomics and Far-western blot}

The cell wall and extracellular proteins of S. suis 2 were subjected to 2D SDS-PAGE and transferred onto PVDF membranes for Far-western blot analysis. According to our previous study (Li et al., 2015b), at least 200 Coomassie blue stained protein spots were identified on the two-dimensional electrophoresis (2-DE) gels (Fig. 1A and D, left panels). Only the IBPs, which were clearly observed on the 2-DE gels, consistent with the positive response spots on the membranes, were selected. In this way, two plBPs (Fig. 1B) and one hIBP (Fig. 1C) from S. suis 2 extracellular proteins were detected. By using the same method, three pIBPs (Fig. 1E) and five hIBPs (Fig. 1F) in cell wall proteins were identified. No positive response spots were detected when the membrane was incubated with BSA (a negative control). The detected protein spots were manually excised from the gels and subjected to analysis by MALDI-TOF-MS. Finally, a total of six IBPs, including four pig pIBPs and five hIBPs, were identified from S. suis 2 surface proteins by 2DFar-western blot immunoassay. All the identified IBPs except enolase were discovered for the first time. Three proteins enolase, FBA, and KAR displayed binding abilities to both plgG and hlgG. The data of the positive spots are listed in Table 2.

\section{Confirmation of the binding activity of pIBPs and hIBPs}

To prove that the identified proteins could interact specifically with plgG or hlgG, the ligand binding assays was further performed by Far-western blot and dot blot analysis. As shown in Fig. 2A and C, recombinant enolase, LysM, Pyk, LDH, FBA, and KAR proteins were purified successfully by Ni-chelating affinity gel. The results indicated that recombinant enolase, LysM, FBA, and KAR were able to interact with plgG (Fig. 2B). The hlgG-binding activity of recombinant enolase, Pyk, LDH, FBA, and KAR were also detected by Far-western blot analysis (Fig. 2D). As expected, plgG and hlgG failed to bind to the negative control protein casein. These data suggested that all the identified IBPs of $S$. suis 2 bind specifically to $\lg G$.

Furthermore, the interaction of recombinant IBPs with plgG or hlgG was also evaluated by dot blot analysis. Our data confirmed that recombinant captured IBPs showed strong binding to plgG (Fig. 3A) and hlgG (Fig. 3B), while the casein, a negative control protein, almost had no specific bind to plgG or hlgG. Under similar assay conditions, no positive response was observed when the membrane was only incubated with the secondary antibody (Fig. 3C). Dot blot analysis demonstrated all the captured S. suis 2 IBPs could interact with IgG, which is in general consistency with the result of the Far-western blot assay.

\section{Identification of enolase regions that interact with plgG and hlgG}

Enolase is a multifunctional surface protein of $S$. suis, which could bind both plgG and hlgG, as well as a variety of host component proteins. However, the binding subdomain of enolase to plgG or hlgG remains unclear. According to the PDB database, the enolase putative domain can be divided into N-terminal and C-terminal portion (Fig. 4A). In an attempt to determine the plgG- and hlgG- binding regions of enolase, we 
engineered two recombinant truncations of enolase mainly according to the PDB database, designated enolase N-terminal portion (Enolase-N, a.a. 4-148) and enolase C-terminal portion (Enolase-C, a.a. 142432), with an overlapping portion of 7 amino acids (Fig. 4B). As shown in Fig. 4C, recombinant Enolase-N and Enolase-C were purified successfully by Ni-chelating affinity gel. The plgG-binding activity of recombinant Enolase-C was detected by Far-western blot analysis, while Enolase-N almost had no specific bind to plgG (Fig. 4D). Furthermore, we detected both Enolase-N and Enolase-C can interact with hlgG, whereas Enolase-C exhibited higher binding activity to hlgG compared with Enolase-N (Fig. 4E). Under similar assay conditions, plgG and hlgG failed to bind to the negative control protein casein. Our results indicated that interactions of enolase with plgG and hlgG is primarily mediated by Enolase-C.

\section{Two distinct regions of the carboxyl terminus bind to different host IgG proteins}

To further determine the plgG- and hlgG- binding regions of Enolase-C, two recombinant truncations of Enolase-C were constructed, designated Enolase-C1 (a.a. 142-271) and Enolase-C2 (a.a. 271-432) (Fig. $5 A)$. After purification by Ni-chelating affinity gel, SDS-PAGE analysis confirmed that recombinant Enolase-C1 and Enolase-C2 were purified successfully (Fig. 5B). As shown in Fig. 5C and D, the binding activity of hlgG to Enolase-C was stronger than plgG. The data showed that Enolase-C possessed two different binding domains (Enolase-C1 and Enolase-C2) with distinct host IgG proteins. We found that plgG were able to interact with Enolase-C1, while we detected no plgG-binding activity for Enolase-C2 (Fig. 5C). Notably, the hlgG-binding ability of Enolase-C2 was detected, while Enolase-C1 almost had no specific bind to hlgG (Fig. 5D). Of particular note, Enolase-C exhibited stronger binding ability to hlgG than Enolase-C2 (Fig. 5D).

\section{Discussion}

S. suis has emerged as an important zoonotic agent that can be transmitted to humans and is responsible for severe financial losses in the global swine industry. It causes septicemia, arthritis, meningitis, and endocarditis in swine (Lun et al., 2007), and also cause serious injuries such as septicemia, meningitis, permanent hearing loss in humans who come into contact with infected pigs or pork-derived products (Gottschalk et al., 2007). In 1998 and 2005, two major outbreaks of human infection caused by S. suis 2 raised enormous public concern in China (Tang et al., 2006; Yu et al., 2006). Strikingly, both outbreaks lead to streptococcal toxic shock syndrome (STSS), which is showed a prevalent feature of acute high fever and high mortality rate despite antibiotic therapy (Sriskandan and Slater, 2006).

IgG is the major antibody of humoral immunity found in extracellular fluid and blood. By binding many kinds of pathogens such as fungi, viruses, and bacteria, IgG can protect the host tissues from infection. The ability to interact with IgG in a non-immune reaction is a feature shared by streptococcal groups (Bessen and Fischetti, 1990). The main purpose of the present study was to search for novel plgG and hlgG-binding proteins in S. suis. Four plBPs and five hIBPs were captured from $S$. suis 2 surface proteins by 2D-Far-western blot assays. The captured proteins were further evaluated their binding ability to plgG 
or hlgG by Far-western blot and dot blot. In general consistency with the results of 2D-Far-western blot, we found that all the identified proteins were able to interact with plgG or hlgG. All the identified IBPs except enolase were discovered for the first time. Four proteins enolase, LDH, FBA, and KAR have been reported as extracellular matrix (ECM) binding proteins, of which enolase, $L D H$, and FBA involved in adherence of S. suis 2 (Li et al., 2015b). Additionally, enolase, Pyk, FBA, and KAR have been identified as factor $\mathrm{H}$ binding proteins in our recent study (Li et al., 2017c). LysM has been documented as a surface protein contributes to $S$. suis 2 virulence. These data provide important clues of $S$. suis pathogenesis.

Enolase, a glycolytic enzyme of the glycolysis pathway, was identified as a highly conserved immunogenic protein, which is present at the surface of all the described $S$. suis serotypes (Esgleas et al., 2008; Feng et al., 2009). It is also a very highly conserved protein among streptococcus species ( $>93 \%$ homology with other streptococcal enolase) (Esgleas et al., 2008; Jing et al., 2008). Previous studies indicated that enolase plays an important role in the adhesion and pathogenesis of $S$. suis with specifically binding activity to many host components. Zhang et al (Zhang et al., 2009) and Feng et al (Feng et al., 2009) had previously demonstrated that enolase could elicit good protection against $S$. suis infection in a mouse model. In this study, we also identified that both plgG and hlgG can specifically interact with enolase. Hence, characterize the binding regions of enolase that interact with plgG or hlgG may give insight into the pathogenesis of $S$. suis.

Collectively, we determined that the binding region of enolase to $\mathrm{PlgG}$ and $\mathrm{hlgG}$ is primarily mediated by Enolase-C (a.a. 142-432). Further results indicated that Enolase-C possessed two different binding domains with distinct host IgG proteins. We found that PlgG were able to interact with the Enolase-C1, while hlgG bind to the Enolase-C2. These data of enolase could contribute to a better understanding of the pathogenesis of $S$. suis induced infection.

\section{Declarations}

\section{Acknowledgments}

Not applicable.

\section{Author contributions}

QL and YF performed the experiments, interpreted the data and wrote the manuscript; GLG and ZHW performed some experiments; WZ participated in experimental design interpreted the data, and supervised the research project. All authors approved the final draft.

\section{Funding}

This study was supported by National Key R\&D Program of China (grant number 2018YFC1602500) \the National Natural Science Foundation of China (grant number 31772751), the Opening Fund of Key Laboratory of Microorganism Technology and Bioinformatics Research of Zhejiang Province (grant number 2017E10010), the Natural Science Foundation of Jiangsu Province (grant number BK20190886), 
the China Postdoctoral Science Foundation (grant number 2019M661953), and A Project Funded by the Priority Academic Program Development of Jiangsu Higher Education Institutions (PAPD).

\section{Availability of data and materials}

Not applicable.

\section{Ethical approval and consent to participate}

Procedures involving the care and use of animals were approved by the Jiangsu Administrative Committee for Laboratory Animals (permission number SYXK-SU-2007-0005) and complied with the Jiangsu Laboratory Animal Welfare and Ethics guidelines of the Jiangsu Administrative Committee of Laboratory Animals.

\section{Consent for publication}

All authors gave their informed consent prior to their inclusion in the study.

\section{Competing interests}

The authors declare that they have no competing interests.

\section{References}

Baums, C.G., Kock, C., Beineke, A., Bennecke, K., Goethe, R., Schroder, C., Waldmann, K.H., ValentinWeigand, P., 2009. Streptococcus suis bacterin and subunit vaccine immunogenicities and protective efficacies against serotypes 2 and 9. Clinical and vaccine immunology : CVI 16, 200-208.

Bessen, D., Fischetti, V.A., 1990. A human IgG receptor of group A streptococci is associated with tissue site of infection and streptococcal class. J Infect Dis 161, 747-754.

Blumenfeld, W., Mandrell, R.E., Jarvis, G.A., Griffiss, J.M., 1990. Localization of host immunoglobulin G to the surface of Pneumocystis carinii. Infection and immunity 58, 456-463.

Chen, B., Zhang, A., Li, R., Mu, X., He, H., Chen, H., Jin, M., 2010. Evaluation of the protective efficacy of a newly identified immunogenic protein, HP0272, of Streptococcus suis. FEMS microbiology letters $307,12-$ 18.

Du, H., Huang, W., Xie, H., Ye, C., Jing, H., Ren, Z., Xu, J., 2013. The genetically modified suilysin, rSLY(P353L), provides a candidate vaccine that suppresses proinflammatory response and reduces fatality following infection with Streptococcus suis. Vaccine 31, 4209-4215.

Esgleas, M., Dominguez-Punaro Mde, L., Li, Y., Harel, J., Dubreuil, J.D., Gottschalk, M., 2009. Immunization with SsEno fails to protect mice against challenge with Streptococcus suis serotype 2. FEMS Microbiol Lett 294, 82-88. 
Esgleas, M., Li, Y., Hancock, M.A., Harel, J., Dubreuil, J.D., Gottschalk, M., 2008. Isolation and characterization of alpha-enolase, a novel fibronectin-binding protein from Streptococcus suis. Microbiology 154, 2668-2679.

Feng, Y., Pan, X., Sun, W., Wang, C., Zhang, H., Li, X., Ma, Y., Shao, Z., Ge, J., Zheng, F., Gao, G.F., Tang, J., 2009. Streptococcus suis enolase functions as a protective antigen displayed on the bacterial cell surface. J Infect Dis 200, 1583-1592.

Feng, Y., Zhang, H., Ma, Y., Gao, G.F., 2010. Uncovering newly emerging variants of Streptococcus suis, an important zoonotic agent. Trends Microbiol 18, 124-131.

Feng, Y., Zhang, H., Wu, Z., Wang, S., Cao, M., Hu, D., Wang, C., 2014. Streptococcus suis infection: an emerging/reemerging challenge of bacterial infectious diseases? Virulence 5, 477-497.

Fittipaldi, N., Segura, M., Grenier, D., Gottschalk, M., 2012. Virulence factors involved in the pathogenesis of the infection caused by the swine pathogen and zoonotic agent Streptococcus suis. Future microbiology 7, 259-279.

Gottschalk, M., Segura, M., Xu, J., 2007. Streptococcus suis infections in humans: the Chinese experience and the situation in North America. Anim Health Res Rev 8, 29-45.

Goyette-Desjardins, G., Auger, J.P., Xu, J., Segura, M., Gottschalk, M., 2014. Streptococcus suis, an important pig pathogen and emerging zoonotic agent-an update on the worldwide distribution based on serotyping and sequence typing. Emerg Microbes Infect 3, e45.

Jacobs, A.A., van den Berg, A.J., Loeffen, P.L., 1996. Protection of experimentally infected pigs by suilysin, the thiol-activated haemolysin of Streptococcus suis. The Veterinary record 139, 225-228.

Jing, H.B., Yuan, J., Wang, J., Yuan, Y., Zhu, L., Liu, X.K., Zheng, Y.L., Wei, K.H., Zhang, X.M., Geng, H.R., Duan, Q., Feng, S.Z., Yang, R.F., Cao, W.C., Wang, H.L., Jiang, Y.Q., 2008. Proteome analysis of Streptococcus suis serotype 2. Proteomics 8, 333-349.

Li, M., Shao, Z.Q., Guo, Y., Wang, L., Hou, T., Hu, D., Zheng, F., Tang, J., Wang, C., Feng, Y., Gao, J., Pan, X., 2015a. The type II histidine triad protein HtpsC is a novel adhesion with the involvement of Streptococcus suis virulence. Virulence 6, 631-641.

Li, Q., Fu, Y., He, Y., Zhang, Y., Qian, Y., Yu, Y., Yao, H., Lu, C., Zhang, W., 2017a. Fibronectin-/fibrinogenbinding protein (FBPS) is not a critical virulence factor for the Streptococcus suis serotype 2 strain ZY05719. Vet Microbiol 208, 38-46.

Li, Q., Fu, Y., Ma, C., He, Y., Yu, Y., Du, D., Yao, H., Lu, C., Zhang, W., 2017b. The non-conserved region of MRP is involved in the virulence of Streptococcus suis serotype 2. Virulence, 1-16. 
Li, Q., Liu, H., Du, D., Yu, Y., Ma, C., Jiao, F., Yao, H., Lu, C., Zhang, W., 2015b. Identification of Novel Laminin- and Fibronectin-binding Proteins by Far-Western Blot: Capturing the Adhesins of Streptococcus suis Type 2. Front Cell Infect Microbiol 5, 82.

Li, Q., Ma, C., Fu, Y., He, Y., Yu, Y., Du, D., Yao, H., Lu, C., Zhang, W., 2017c. Factor H specifically capture novel Factor H-binding proteins of Streptococcus suis and contribute to the virulence of the bacteria. Microbiological research 196, 17-25.

Lu, L., Ma, Z., Jokiranta, T.S., Whitney, A.R., DeLeo, F.R., Zhang, J.R., 2008. Species-specific interaction of Streptococcus pneumoniae with human complement factor H. J Immunol 181, 7138-7146.

Lun, Z.R., Wang, Q.P., Chen, X.G., Li, A.X., Zhu, X.Q., 2007. Streptococcus suis. an emerging zoonotic pathogen. The Lancet. Infectious diseases 7, 201-209.

Nobbs, A.H., Lamont, R.J., Jenkinson, H.F., 2009. Streptococcus adherence and colonization. Microbiology and molecular biology reviews : MMBR 73, 407-450, Table of Contents.

Pian, Y., Gan, S., Wang, S., Guo, J., Wang, P., Zheng, Y., Cai, X., Jiang, Y., Yuan, Y., 2012. Fhb, a novel factor $\mathrm{H}$-binding surface protein, contributes to the antiphagocytic ability and virulence of Streptococcus suis. Infection and immunity 80, 2402-2413.

Pian, Y., Wang, P., Liu, P., Zheng, Y., Zhu, L., Wang, H., Xu, B., Yuan, Y., Jiang, Y., 2015. Proteomics identification of novel fibrinogen-binding proteins of Streptococcus suis contributing to antiphagocytosis. Front Cell Infect Microbiol 5, 19.

Serhir, B., Dubreuil, D., Higgins, R., Jacques, M., 1995. Purification and characterization of a 52-kilodalton immunoglobulin G-binding protein from Streptococcus suis capsular type 2. Journal of bacteriology 177 , 3830-3836.

Serhir, B., Higgins, R., Foiry, B., Jacques, M., 1993. Detection of immunoglobulin-G-binding proteins in Streptococcus suis. Journal of general microbiology 139, 2953-2958.

Sriskandan, S., Slater, J.D., 2006. Invasive disease and toxic shock due to zoonotic Streptococcus suis: an emerging infection in the East? PLoS Med 3, e187.

Staats, J.J., Feder, I., Okwumabua, O., Chengappa, M.M., 1997. Streptococcus suis: past and present. Vet Res Commun 21, 381-407.

Sun, Y., Li, N., Zhang, J., Liu, H., Liu, J., Xia, X., Sun, C., Feng, X., Gu, J., Du, C., Han, W., Lei, L., 2016. Enolase of Streptococcus Suis Serotype 2 Enhances Blood-Brain Barrier Permeability by Inducing IL-8 Release. Inflammation 39, 718-726.

Tang, J., Wang, C., Feng, Y., Yang, W., Song, H., Chen, Z., Yu, H., Pan, X., Zhou, X., Wang, H., Wu, B., Wang, H., Zhao, H., Lin, Y., Yue, J., Wu, Z., He, X., Gao, F., Khan, A.H., Wang, J., Zhao, G.P., Wang, Y., Wang, X., Chen, 
Z., Gao, G.F., 2006. Streptococcal toxic shock syndrome caused by Streptococcus suis serotype 2. PLoS medicine 3, e151.

Widders, P.R., Dorrance, L.A., Yarnall, M., Corbeil, L.B., 1989. Immunoglobulin-binding activity among pathogenic and carrier isolates of Haemophilus somnus. Infection and immunity 57, 639-642.

Wisselink, H.J., Vecht, U., Stockhofe-Zurwieden, N., Smith, H.E., 2001. Protection of pigs against challenge with virulent Streptococcus suis serotype 2 strains by a muramidase-released protein and extracellular factor vaccine. Vet Rec 148, 473-477.

Yu, H., Jing, H., Chen, Z., Zheng, H., Zhu, X., Wang, H., Wang, S., Liu, L., Zu, R., Luo, L., Xiang, N., Liu, H., Liu, X., Shu, Y., Lee, S.S., Chuang, S.K., Wang, Y., Xu, J., Yang, W., Streptococcus suis study, g., 2006. Human Streptococcus suis outbreak, Sichuan, China. Emerg Infect Dis 12, 914-920.

Zhang, A., Chen, B., Mu, X., Li, R., Zheng, P., Zhao, Y., Chen, H., Jin, M., 2009. Identification and characterization of a novel protective antigen, Enolase of Streptococcus suis serotype 2. Vaccine 27, 1348-1353.

Zhang, H., Zheng, J., Yi, L., Li, Y., Ma, Z., Fan, H., Lu, C., 2014. The identification of six novel proteins with fibronectin or collagen type I binding activity from Streptococcus suis serotype 2. Journal of microbiology $52,963-969$.

\section{Tables}

Table 1. Primers used in this study. 


\begin{tabular}{|c|c|c|c|}
\hline Primers & Sequences $(5 \hat{c}-3 \hat{c})^{a}$ & $\begin{array}{l}\text { Length of PCR } \\
\text { products }(\mathrm{bp})\end{array}$ & Function \\
\hline Enolase-F & CGCGGATCCATGTCAATTATTACTGATGTT & \multirow[t]{2}{*}{1308} & \multirow{2}{*}{$\begin{array}{l}\text { The ORF of } \\
\text { Enolase }\end{array}$} \\
\hline Enolase-R & CCGETCGAGTTATTTTTTCAAGTTGTAGAA & & \\
\hline LysM-F & CGCGGATCCCCACAACATATGCGTCGCAAG & \multirow[t]{2}{*}{990} & \multirow{2}{*}{$\begin{array}{l}\text { The ORF of } \\
\text { LysM }\end{array}$} \\
\hline LysM-R & CCGGAATTCCACATGATCGTAGTGGTTTTC & & \\
\hline Pyk-F & CGCGGATCCGCAACCCTTGGTCCAGCGGTA & \multirow[t]{2}{*}{1476} & \multirow{2}{*}{$\begin{array}{l}\text { The ORF of } \\
\text { Pyk }\end{array}$} \\
\hline Pyk-R & CCGETCGAGTTATACTGTACGAACACGCATAGT & & \\
\hline LDH-F & CGCGGATCCACTGCAACTAAACAACACAAA & \multirow[t]{2}{*}{978} & \multirow{2}{*}{$\begin{array}{l}\text { The ORF of } \\
\text { LDH }\end{array}$} \\
\hline LDH-R & CCGCTCGAGTTAGTTTTTTACACCAGCTGCAAT & & \\
\hline FBA-F & CGCGGATCCACAAACAACCTTGAGTGGACT & \multirow[t]{2}{*}{798} & \multirow{2}{*}{$\begin{array}{l}\text { The ORF of } \\
\text { FBA }\end{array}$} \\
\hline FBA-R & CCGCTCGAGCGCTGAACCGAATACGTCGAT & & \\
\hline KAR-F & CGCGGATCCCTGCATGGTCAAGCCTCCGTC & \multirow[t]{2}{*}{732} & \multirow{2}{*}{$\begin{array}{l}\text { The ORF of } \\
\text { KAR }\end{array}$} \\
\hline KAR-R & CCGCTCGAGGTAACAGGTTCAAGTCGAGGA & & \\
\hline $\begin{array}{l}\text { Enolase- } \\
\mathrm{N}-\mathrm{F}\end{array}$ & CGCGGATCCATTACTGATGTTTACGCTCGC & \multirow[t]{2}{*}{435} & \multirow[t]{2}{*}{$\begin{array}{l}\text { The ORF of } \\
\text { Enolase-N }\end{array}$} \\
\hline $\begin{array}{l}\text { Enolase- } \\
\mathrm{N}-\mathrm{R}\end{array}$ & 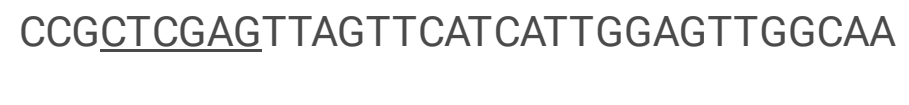 & & \\
\hline $\begin{array}{l}\text { Enolase- } \\
\mathrm{C}-\mathrm{F}\end{array}$ & CGCGGATCCTTGCCAACTCCAATGATGAAC & \multirow[t]{2}{*}{873} & \multirow[t]{2}{*}{$\begin{array}{l}\text { The ORF of } \\
\text { Enolase-C }\end{array}$} \\
\hline $\begin{array}{l}\text { Enolase- } \\
\mathrm{C}-\mathrm{R}\end{array}$ & 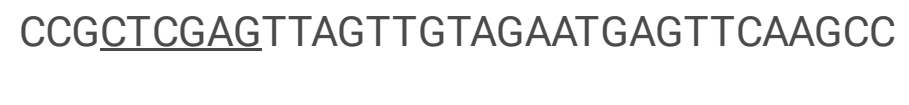 & & \\
\hline $\begin{array}{l}\text { Enolase- } \\
\mathrm{C} 1-\mathrm{F}\end{array}$ & CGCGGATCCTTGCCAACTCCAATGATGAAC & \multirow[t]{2}{*}{390} & \multirow[t]{2}{*}{$\begin{array}{l}\text { The ORF of } \\
\text { Enolase-C1 }\end{array}$} \\
\hline $\begin{array}{l}\text { Enolase- } \\
\text { C1-R }\end{array}$ & CCGCTCGAGTGTACGAACAGCAGCGCCTTC & & \\
\hline $\begin{array}{l}\text { Enolase- } \\
\mathrm{C} 2-\mathrm{F}\end{array}$ & CGCGGATCCACATCTGCAGAACAAATCGAC & \multirow[t]{2}{*}{486} & \multirow[t]{2}{*}{$\begin{array}{l}\text { The ORF of } \\
\text { Enolase-C2 }\end{array}$} \\
\hline $\begin{array}{l}\text { Enolase- } \\
\mathrm{C} 2-\mathrm{R}\end{array}$ & CCGETCGAGTTAGTTGTAGAATGAGTTCAAGCC & & \\
\hline
\end{tabular}

aThe underlined sequences are restriction enzyme sites.

Table 2. Identification of the potential human and pig IgG-binding proteins by MALDI-TOF-MS. 


\begin{tabular}{|c|c|c|c|c|c|c|}
\hline $\begin{array}{l}\text { Spot } \\
\text { no. }{ }^{a}\end{array}$ & Identified protein & $\begin{array}{l}\text { Accession } \\
\text { no. }\end{array}$ & $\begin{array}{l}\text { Theoretical } \\
\mathrm{pl} / \mathrm{MW}^{\mathrm{b}}\end{array}$ & $\begin{array}{l}\text { Experimental } \\
\mathrm{pl} / \mathrm{MW}\end{array}$ & $\begin{array}{l}\text { MASCOT } \\
\text { score }\end{array}$ & $\begin{array}{l}\text { Coverage } \\
(\%)\end{array}$ \\
\hline 1 & $\begin{array}{l}\text { Peptidoglycan- } \\
\text { binding protein } \\
\text { LysM }\end{array}$ & AKG39650.1 & $4.52 / 37564$ & $4.2 / 45000$ & 117 & 63 \\
\hline 2,3 & Enolase & AKG40756.1 & $4.66 / 47095$ & $4.7 / 50000$ & 143 & 36 \\
\hline 4 & Pyruvate kinase & AKG39916.1 & $5.12 / 54630$ & $5.2 / 57000$ & 351 & 54 \\
\hline 5 & $\begin{array}{l}\text { Lactate } \\
\text { dehydrogenase }\end{array}$ & AKG40380.1 & $5.05 / 35422$ & $5.0 / 37000$ & 258 & 42 \\
\hline 6 & $\begin{array}{l}\text { Fructose- } \\
\text { bisphasphate } \\
\text { aldolase }\end{array}$ & AKG39743.1 & $4.90 / 31155$ & $4.9 / 32000$ & 375 & 44 \\
\hline 7 & $\begin{array}{l}\text { 3-Ketoacyl-ACP } \\
\text { reductase }\end{array}$ & AKG41028.1 & $5.53 / 25589$ & $5.7 / 25000$ & 263 & 29 \\
\hline
\end{tabular}

aspot numbers correspond to those indicated in Figure 1.

${ }^{\mathrm{b}}$ Theoretical $\mathrm{pl}$ and $\mathrm{MW}$ were calculated using the Compute $\mathrm{pl} / \mathrm{Mw}$ server (http://web.expasy.org/compute_pi/).

\section{Figures}




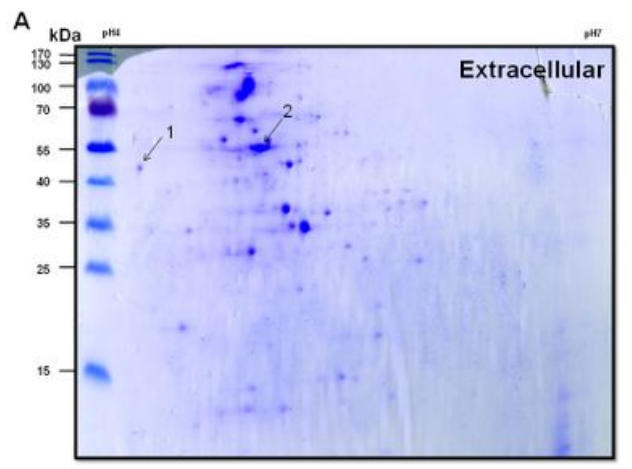

SDS-PAGE

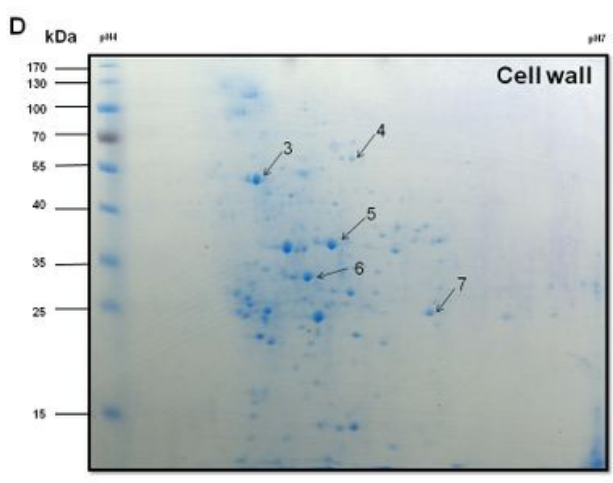

SDS-PAGE

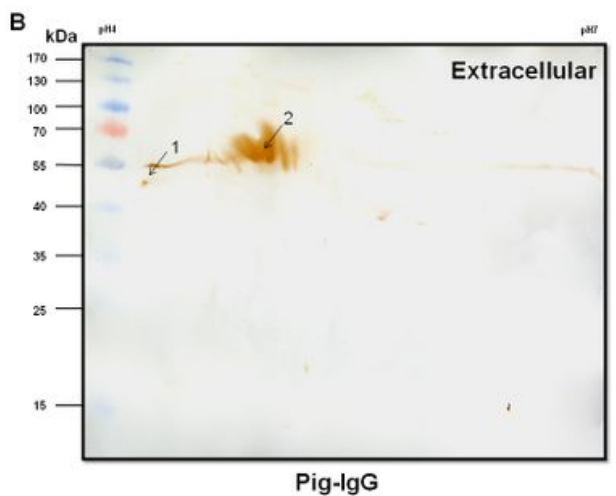

Pig-lgG

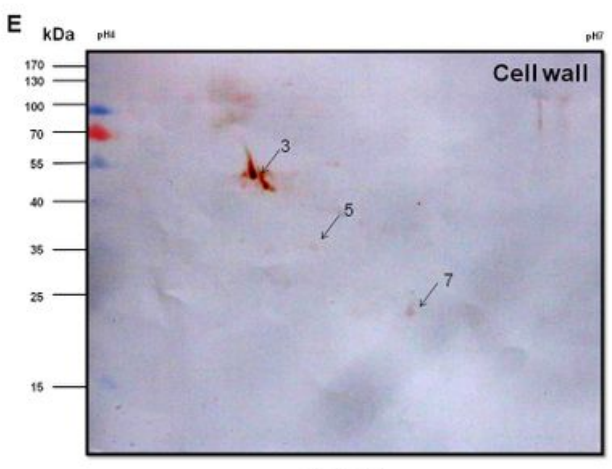

Pig-IgG

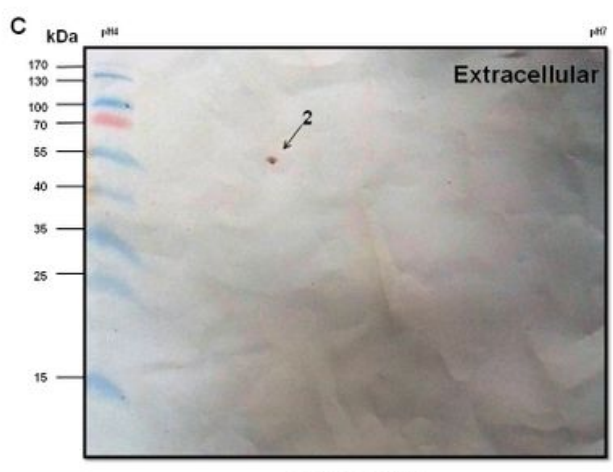

Human-IgG

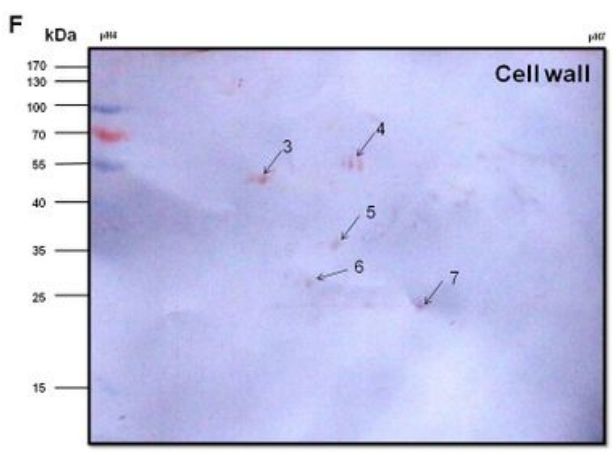

Human-IgG

\section{Figure 1}

2-DE profiles and Far-western blot to identify the affinity of plgG and hlgG interactions with S. suis 2 cell wall and extracellular proteins. The cell wall and extracellular proteins of $\mathrm{S}$. suis 2 were loaded into immobilized pH gradient strips for IEF analysis and by SDS-PAGE in the second dimension. The 2-DE gels were transferred onto PVDF membranes and incubated with plgG or hlgG. Arrows indicate pIBPs or hIBPs detected with HRP conjugated SPA. (A) 2-DE gel of S. suis 2 extracellular proteins. (B) Far-western blot of extracellular proteins incubated with plgG. (C) Far-western blot of extracellular proteins incubated with hlgG. (D) 2-DE gel of S. suis 2 cell wall proteins. (E) Far-western blot of cell wall proteins incubated with plgG. (F) Far-western blot of cell wall proteins incubated with hlgG. 


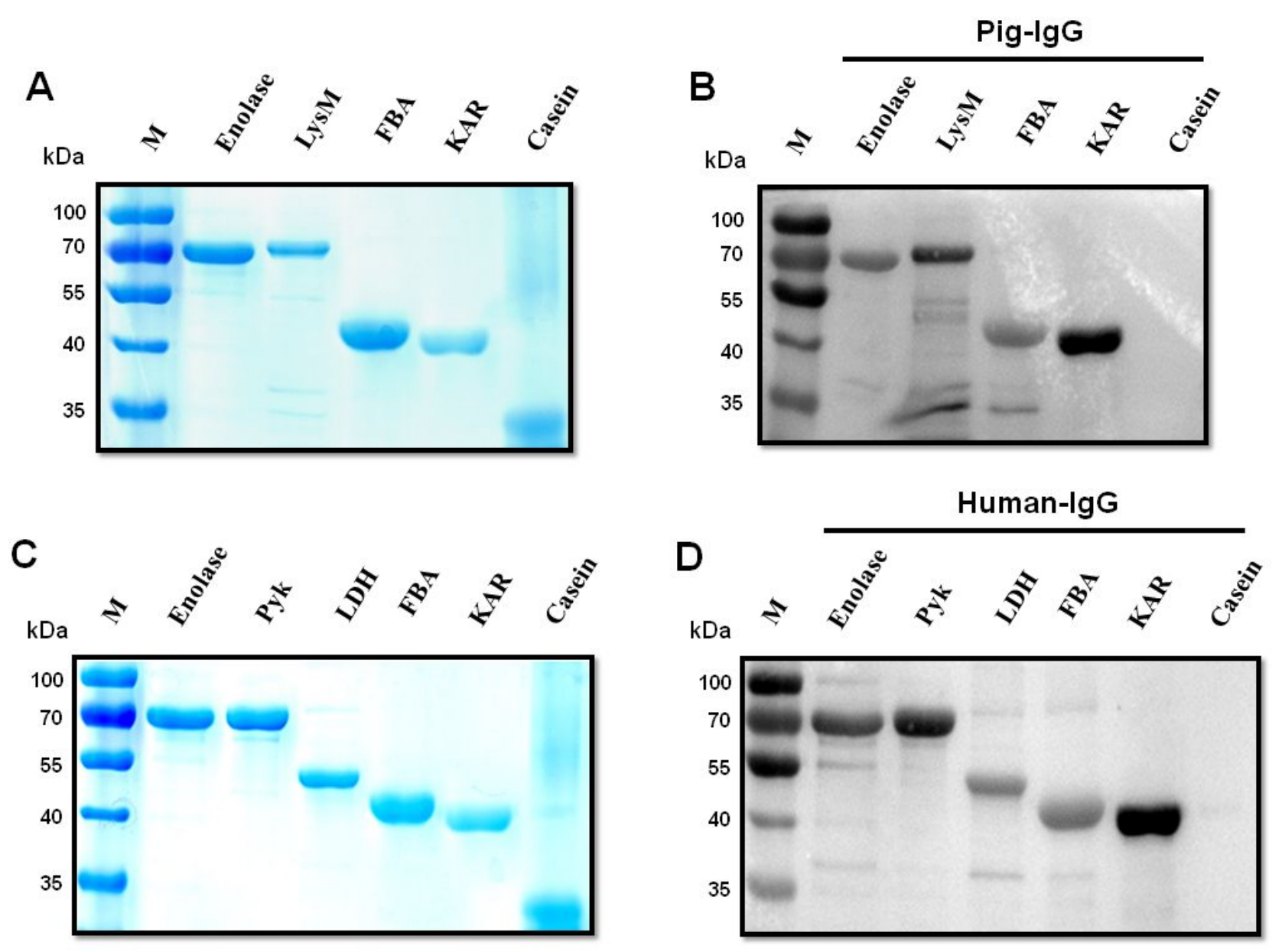

\section{Figure 2}

Identification the binding of plgG or hlgG to IBPs of S. suis 2 by Far-western blot. SDS-PAGE $(A, C)$ and Far-western blot analysis (B, D) of the S. suis 2 recombinant IBPs. Recombinant proteins (Enolase, LysM, Pyk, LDH, FBA, KAR) and casein were subjected to SDS-PAGE, then transferred onto PVDF membranes and incubated with plgG or hlgG. Bound plgG or hlgG was recognized with HRP conjugated SPA. Casein was used as a negative control for non-specific binding to lgG. 

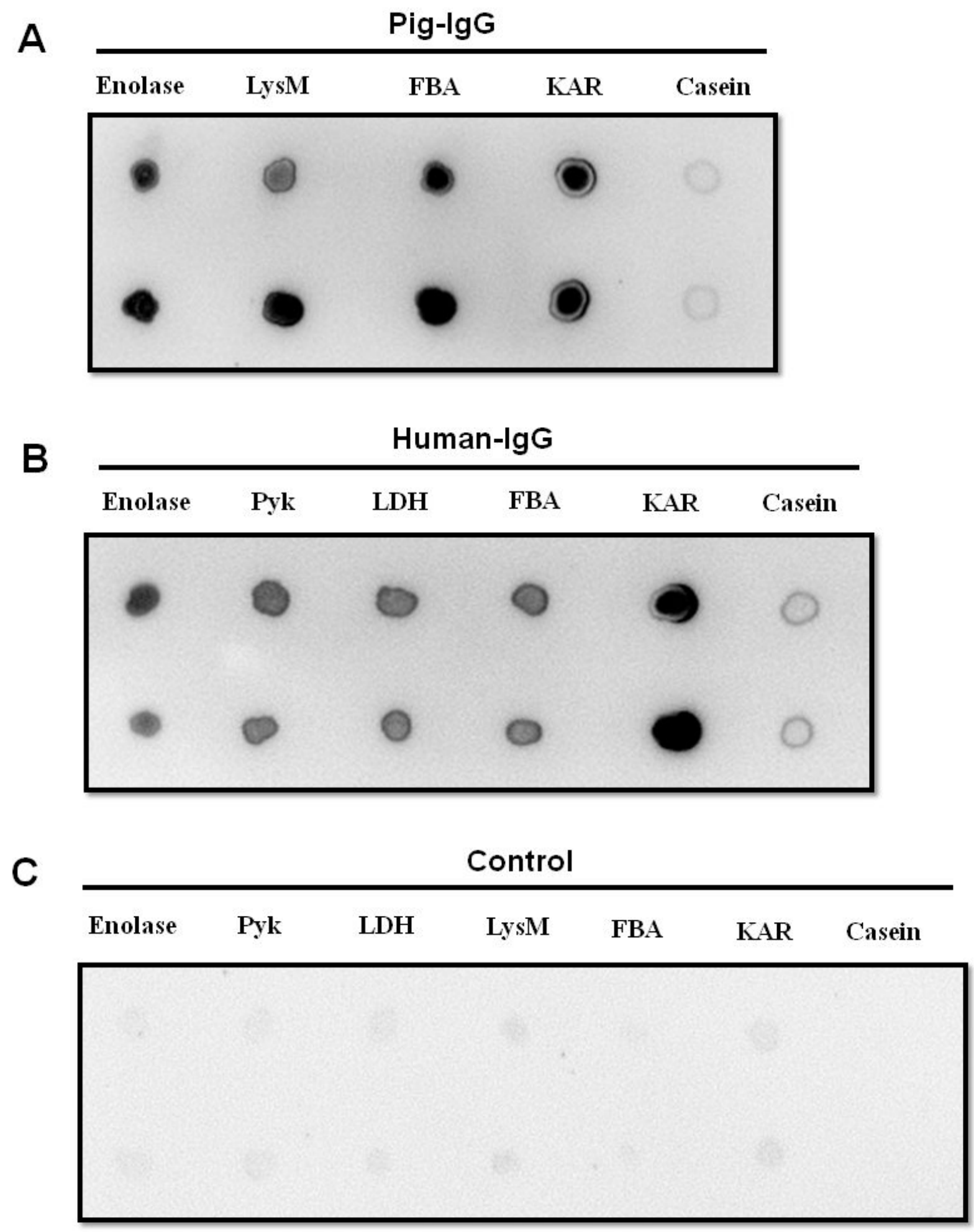

\section{Figure 3}

Identification the binding of plgG or hlgG to IBPs of S. suis 2 by dot blot. Recombinant pIBPs $(A)$ and hIBPs (B) were spotted onto the methanol-activated PVDF membranes and incubated with plgG or hlgG. Bound plgG or hlgG was recognized with HRP conjugated SPA. Casein was used as a negative control for non-specific binding to IgG and the membrane with HRP conjugated SPA alone were used as a blank control. 
A

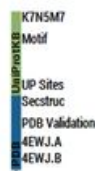

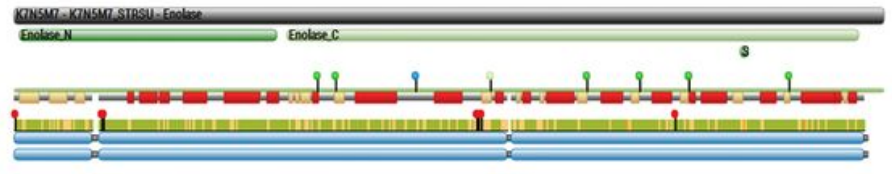

B
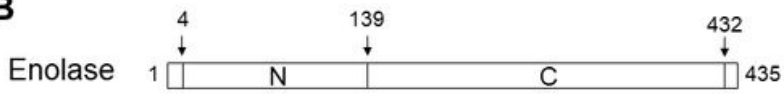

Enolase-N 4

Enolase-C

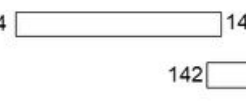

148 432

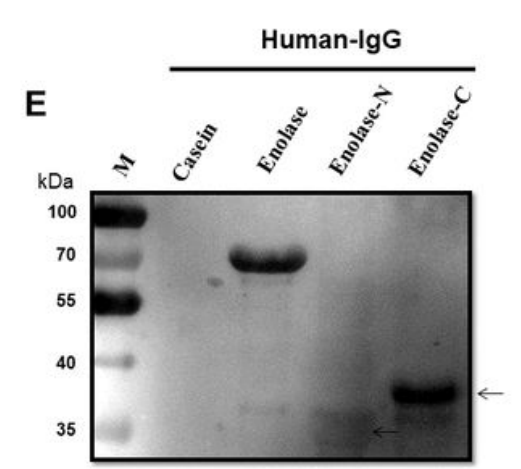

\section{Figure 4}
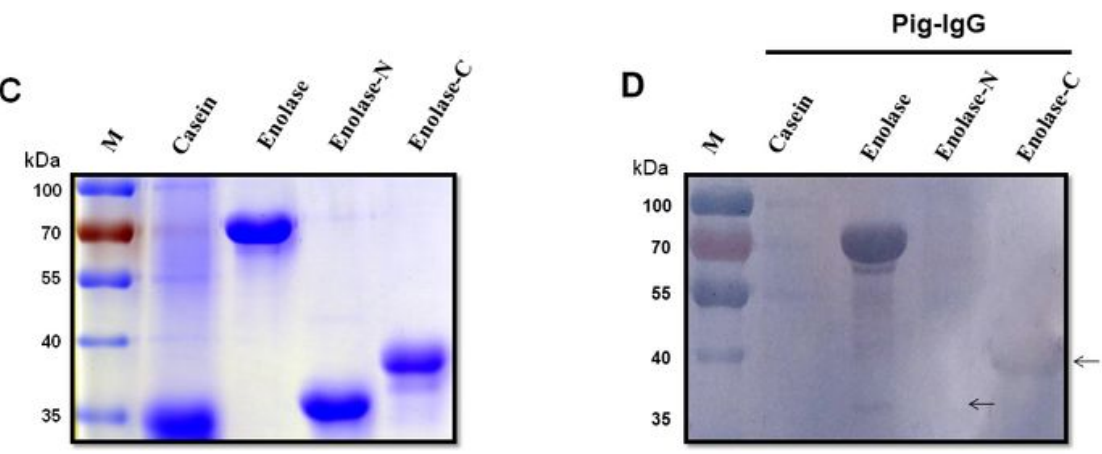

Interaction of S. suis 2 enolase and its regions with plgG or hlgG. (A) The enolase putative domain predicted by the PDB database. (B) Schematic representation of two recombinant truncations of enolase (Enolase-N and Enolase-C). The truncations of enolase were engineered mainly according to the PDB database. (C) SDS-PAGE analysis of recombinant enolase, Enolase-N, and Enolase-C. (D) Far-western blot analysis of enolase and its truncations incubated with plgG. (E) Far-western blot analysis of enolase and its truncations incubated with hlgG. 
A

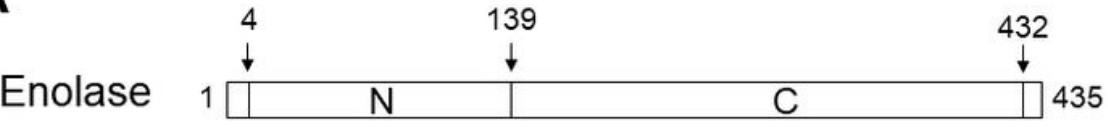

Enolase-C1

Enolase-C2
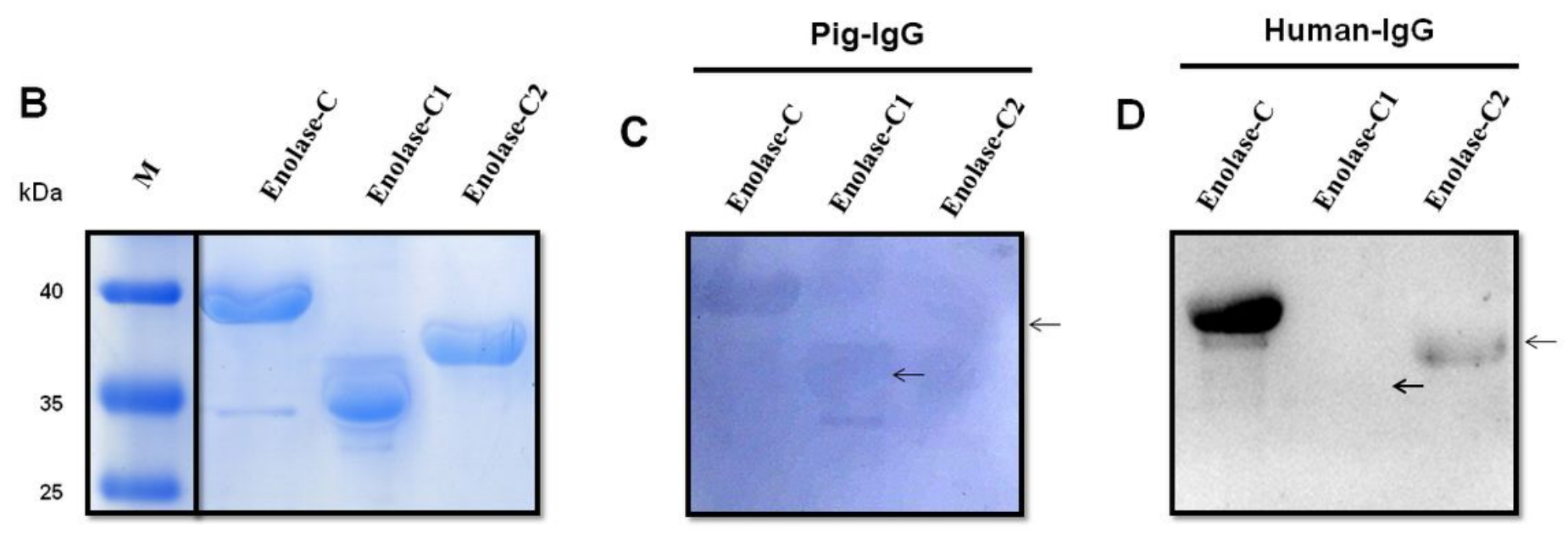

142 271

271 432

Figure 5

Characterization of enolase truncations that interact with plgG or hlgG. (A) Schematic representation of two deletion constructs Enolase-C1 and Enolase-C2. (B) SDS-PAGE analysis of recombinant Enolase-C, Enolase-C1, and Enolase-C2. (C) Far-western blot analysis of Enolase-C and its truncations incubated with plgG. (D) Far-western blot analysis of Enolase-C and its truncations incubated with hlgG. 